\title{
Sexual dysfunctions and short-term glucose variability in young men with type 1 diabetes
}

\author{
Paola Caruso $^{1,2} \cdot$ Paolo Cirillo $^{1} \cdot$ Carla Carbone ${ }^{1,2} \cdot$ Annalisa Sarnataro $^{1} \cdot$ Maria Ida Maiorino $^{1,3}$ (1) \\ Giuseppe Bellastella $^{1,2}$ (i) $\cdot$ Katherine Esposito ${ }^{1,3}$ (])
}

Received: 15 October 2020 / Accepted: 19 April 2021 / Published online: 30 April 2021

(c) The Author(s) 2021

\begin{abstract}
Purpose Erectile dysfunction (ED) and premature ejaculation (PE) are common sexual disorders in people with diabetes. Glucose variability $(\mathrm{GV})$ has been recognized as a predictor of microvascular complications. The aim of this study was to investigate the relationship between glucose variability and sexual dysfunctions in young men with type 1 diabetes.

Methods One hundred and twelve patients with type 1 diabetes, aged 18-30 years, were enrolled. Patients were divided into two groups according to glucose variability [group 1 (high GV with coefficient of variation $\geq 36 \%$ )] and group 2 (low GV with coefficient of variation $<36 \%)$ ). The presence of sexual dysfunctions was investigated with validated questionnaires. Results ED and PE prevalence rates in group 1 were $26 \%$ and 13\%, respectively. Similarly, in group 2, the prevalence of ED was $24 \%$, and the prevalence of PE was $13 \%$. In both groups, no significant associations between sexual dysfunctions and parameters of glucose variability were found. Multiple regression analysis identified age and depression as independent predictors of ED and PE.

Conclusion Young male patients affected by type 1 diabetes with high or low glucose variability show a similar prevalence of sexual dysfunctions. ED is the most common sexual dysfunction in diabetic men. Age and depression were the only independent predictive factors for sexual dysfunctions in this population.
\end{abstract}

Keywords Type 1 diabetes $\cdot$ Glucose variability $\cdot$ Erectile dysfunction $\cdot$ Premature ejaculation $\cdot$ Sexual dysfunction

\section{Introduction}

Diabetes is one of the most common chronic diseases in nearly all countries worldwide and a well-known risk factor for sexual dysfunctions in men [1]. Erectile dysfunction (ED) is defined as the persistent or recurrent inability to achieve and/or maintain penile erection sufficient for satisfactory sexual performance [2]. ED is a common sexual arousal disorder in men with diabetes [3], a threefold increased risk having been documented in the Massachusetts

Maria Ida Maiorino

mariaida.maiorino@unicampania.it

1 Department of Advanced Medical and Surgical Sciences, University of Campania “Luigi Vanvitelli”, Piazza L. Miraglia 2, 80138 Naples, Italy

2 Division of Endocrinology and Metabolic Diseases, University of Campania “Luigi Vanvitelli”, Naples, Italy

3 Unit of Diabetes, University of Campania "Luigi Vanvitelli”, Naples, Italy
Male Aging Study [4] as compared to nondiabetic men. ED generally occurs 10-15 years sooner in men with diabetes [4] than in those who do not suffer from diabetes and is more severe [5] and less responsive to oral drugs [6, 7], leading to a reduction in quality of life $[5,8]$. Whether hyperglycemia is a risk factor for the development of ED in diabetic men is still not clear. Some observational studies have shown a relationship between poor glycemic control, expressed by elevated levels of glycated hemoglobin $\left(\mathrm{HbA}_{1 \mathrm{c}}\right)$ and $\mathrm{ED}[5$, $9,10]$, whereas other studies did not report any association [11].

While ED is a well-known diabetes-related sexual dysfunction, ejaculatory and sexual desire issues may also occur in men. Premature ejaculation (PE) is the most frequent male sexual dysfunction, although the true prevalence of this sexual disorder is unclear. The second International Society of Sexual Medicine Ad Hoc Committee for the Definition of Premature Ejaculation [12] defined PE (lifelong and acquired) as a male sexual dysfunction characterized by an ejaculation that occurs sooner than desired after vaginal 
penetration on all or most occasions, or inability to delay ejaculation during sexual intercourse with generation of individual distress, bother, and frustration that negatively impact on the couple's relationship. In several observational studies, the prevalence of PE has been reported to be higher in diabetic men as compared to healthy controls $[13,14]$. Moreover, diabetic people were found to have a higher incidence of PE with increased severity of ED compared to the general population $[13,15]$.

The correlation between glycemic control and microvascular complications is well known in both type 1 and type 2 diabetes [12, 16-20]. Moreover, glycemic variability (GV), defined as the frequency and amplitude of glycemic excursions around the mean of glucose values, expressed using standard deviation or other indices, has emerged as an independent predictor of these complications [21-23]. Indeed, GV has been associated with poor glycemic control, poor quality of life, and increased risk of diabetes-related complications [24].

To the best of our knowledge, there are no studies evaluating the role of GV in sexual dysfunctions in men with type 1 diabetes. Therefore, the aim of the present study was to assess the relationship between $\mathrm{GV}$ and sexual dysfunctions in young men with type 1 diabetes.

\section{Materials and methods}

\section{Participants}

This is a single-center, cross-sectional study aimed at evaluating the influence of GV on sexual dysfunctions in young men with type 1 diabetes admitted to the Unit of Diabetes at the Teaching Hospital of the University of Campania "Luigi Vanvitelli," Naples, Italy. From January to June 2020, men were included in the study if they (1) were aged $\geq 18$ and $\leq 30$ years, (2) had stable couple relationship or sexual activity (masturbation) in the previous month, and (3) did not use phosphodiesterase type 5 inhibitors (PDE5-i). Exclusion criteria were considered the presence of any chronic diseases not including diabetes complications (neoplasms, severe neurodegenerative diseases, major depression or other psychiatric disorders, hypogonadism, penis disorders, drug or alcohol abuse), the use of drugs associated with adverse effects on erectile function, a history of urological surgery, lower urinary tract symptoms, and pelvic trauma in the last 6 months.

\section{Assessment of sexual function}

All participants in the study were asked to complete the Italian version of three different validated multiple-choice self-reported questionnaires assessing both erectile and ejaculatory functions and the presence of depressive symptoms. Participants in the study received a short explanation in order to answer each questionnaire in the context of the visit to our diabetes unit.

Erectile function was investigated by completing the abbreviated form of the International Index of Erectile Function (IIEF-5) [25], which comprises items 2, 4, 5, 7, and 15 of the full scale IIEF-15 and assures simplicity and immediacy in its compilation. According to the recommended scoring system, a total score of 21 or less indicates the presence of ED. ED was classified as mild with a score ranging from 21 to 17 , mild to moderate with a score ranging from 16 to 12 , moderate with a score ranging from 11 to 8 , and severe with a score lower or equal to 7 .

In accordance with the European Association of Urology guidelines [26], we used the five-item premature ejaculation diagnostic tool (PEDT) [27] to assess PE and investigate control of ejaculatory function, frequency, minimal stimulation, and both distress and interpersonal difficulty. A score of 8 or lowerexcluded a diagnosis of PE.

\section{Evaluation of depressive symptoms}

The 13-item short form of the Beck Depression Inventory (BDI) [28] was used to assess the presence of depressive symptoms. This self-report questionnaire covers affective, psychological, and somatic symptoms associated with depression. Each item is scored ranging from 0 to 3 . Four ranges were identified: normal $(<10)$, mildly depressed (10-19), moderately depressed (20-29), and severely depressed $(>30)$.

\section{Assessment of glucose variability}

All patients underwent for 14 days a blinded continuous glucose monitoring (DexCom G5 CGM system-Dexcom Inc., San Diego, USA), composed of a 7-day transcutaneous sensor, a transmitter, and a receiver. The sensor was implanted in the anterior abdominal wall and changed after the first 7 days by the patients. Moreover, the men were instructed to perform the sensor calibration procedure, according to the manufacturer's instructions, within $2 \mathrm{~h}$ from placing the sensor, and then every $12 \mathrm{~h}$. Glucose data were downloaded with Dexcom CLARITY and analyzed by displaying the ambulatory glucose profile (AGP). We assessed GV by collecting the coefficient of variation (CV) from AGP. CV was estimated as the ratio of the standard deviation of glucose values and mean glucose multiplied per 100; values equal to or above $36 \%$ indicated high GV [29]. We also calculated the time in range (TIR) as the percentage of time spent in the glucose range between 70 and $180 \mathrm{mg} / \mathrm{dL}$. Moreover, 
mean daily glucose values and standard deviation (Stdev) were also collected.

\section{Anthropometric measures and laboratory analyses}

The height and weight of each participant were measured using a Seca 200 scale (Seca, Hamburg, Germany) with an annexed stadiometer. Body mass index (BMI) was calculated as weight (in kilograms) divided by height (expressed in meters squared). Waist circumference was also measured. At the end of clinical examination, arterial blood pressure was measured three times while subjects were sitting after 15 min resting. Patients whose average blood pressure levels were equal to or higher than $140 / 90 \mathrm{mmHg}$ or who used antihypertensive medication were classified as affected by hypertension.

Assays for fasting glucose, $\mathrm{HbA}_{1 \mathrm{c}}$, total cholesterol, lowdensity (LDL) and high-density (HDL) lipoprotein cholesterol, triglyceride levels, and testosterone were performed in the hospital's chemistry laboratory.

\section{Statistical analysis}

Sample size calculation was made on the basis of a previous study investigating the relationship between sexual function, measured as Female Sexual Function Index (FSFI) total score, and GV in a population of young women with type 1 diabetes [30]. With an expected Pearson correlation coefficient between the IIEF-5 score and the CV of 0.3 , a sample size of 102 patients was required assuming a power of $0.80 \%$, a $20 \%$ rate of non-responders, and a level of significance of 0.05. Data in tables and figures concerning normally distributed variables are presented as mean $\pm \mathrm{SD}$, while non-normally distributed continuous variables are presented as median (interquartile range). Differences between groups were evaluated by the two-sided Student's $t$-test or Wilcoxon-Mann-Whitney test. The $\chi^{2}$-test was used to compare dichotomous variables. Statistical associations between normally distributed variables were assessed using Pearson's correlation test. Multivariable regression analysis tested the contribution of independent variables (age, duration of diabetes, weight, BMI, waist circumference and BDI) to the dependent variable (IIEF-5 score and PEDT score). Two-sided $P$ values $<0.05$ were considered statistically significant. All statistical analyses were performed using SPSS software.

\section{Results}

One hundred and thirty-six patients were considered eligible to be included in the study; 16 men refused to complete the IIEF-5 questionnaire and eight of the remaining 120 men were excluded because they were not sexually active.
Fig. 1 Process of patients' selection. CV, coefficient of variation; IIEF-5, international index of erectile function

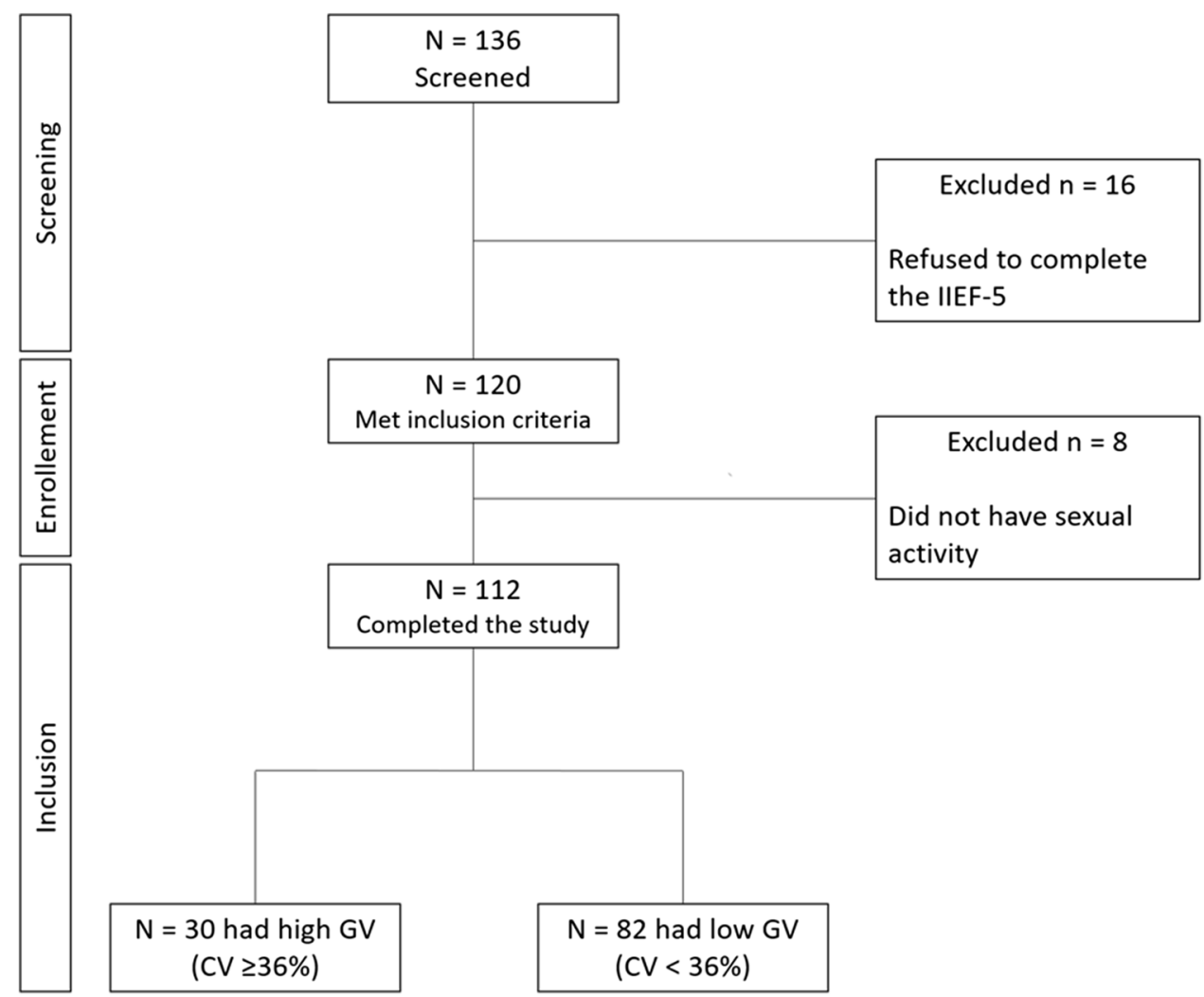


Table 1 Baseline characteristics of diabetic patients

\begin{tabular}{|c|c|}
\hline Parameters & $\begin{array}{l}\text { Patients with } \\
\text { type } 1 \text { diabetes } \\
(n=112)\end{array}$ \\
\hline Age, years & $25.8 \pm 7.5$ \\
\hline Diabetes duration, years & $14 \pm 6.7$ \\
\hline Weight, kg & $76 \pm 11.8$ \\
\hline BMI, $\mathrm{kg} / \mathrm{m}^{2}$ & $25 \pm 3.2$ \\
\hline Waist circumference, $\mathrm{cm}$ & $83.8 \pm 8.9$ \\
\hline $\mathrm{BMI} \geq 25 \mathrm{~kg} / \mathrm{m}^{2}, n(\%)$ & $53(47)$ \\
\hline $\mathrm{FG}, \mathrm{mg} / \mathrm{dL}$ & $168 \pm 69.5$ \\
\hline $\mathrm{HbA}_{1 \mathrm{c}}, \%$ & $7.8 \pm 1.2$ \\
\hline $\mathrm{HbA}_{1 \mathrm{c}}>7, n(\%)$ & $85(76)$ \\
\hline $\mathrm{HR}, \mathrm{bpm}$ & $80.1 \pm 6.1$ \\
\hline SBP & $125(120,130)$ \\
\hline DBP & $80(70,80)$ \\
\hline Total cholesterol & $160.8 \pm 31.9$ \\
\hline HDL cholesterol & $51.5 \pm 11$ \\
\hline LDL cholesterol & $97.3 \pm 27.1$ \\
\hline Triglyceride & $93 \pm 61.7$ \\
\hline Testosterone, $(\mathrm{nmol} / \mathrm{L})$ & $23.6 \pm 5.2$ \\
\hline Microvascular complications, $n(\%)$ & $9(8)$ \\
\hline Autoimmune diseases, $n(\%)$ & $14(12.5)$ \\
\hline MDI/CSII, $n$ & $66 / 44$ \\
\hline Insulin dose, UI per day & $51.3 \pm 15.1$ \\
\hline Insulin dose, UI/kg & $0.68 \pm 0.18$ \\
\hline IIEF-5 & $22 \pm 3.5$ \\
\hline PEDT & $3.5 \pm 3.5$ \\
\hline BDI & $2.2 \pm 2.1$ \\
\hline $\mathrm{CV}, \%$ & $32.5 \pm 11.4$ \\
\hline $\mathrm{CV} \geq 36, n(\%)$ & $23(26.1)$ \\
\hline $\operatorname{TIR}(\%)$ & 68.7 \\
\hline $\mathrm{ED}, \mathrm{n}(\%)$ & $28(25)$ \\
\hline PE, n (\%) & 13 (11.6) \\
\hline Mean daily glucose, $\mathrm{mmol} / \mathrm{L}$ & $10 \pm 2.5$ \\
\hline Stdev, mmol/L & $3.2 \pm 1.2$ \\
\hline
\end{tabular}

Data are expressed as mean $\pm \mathrm{SD}$, median (interquartile range), or number and percentage. Abbreviations: $B D I$ beck depression inventory, $B M I$ body mass index, $C S I I$ continuous subcutaneous insulin infusion, $C V$ coefficient of variation, $D B P$ diastolic blood pressure, $E D$ erectile dysfunction, $F G$ fasting glucose, $H D L$ high density lipoprotein, $H R$ heart rate, $I I E F-5$ international index of erectile function-5, $L D L$ low density lipoprotein, $M D I$ multiple daily injection, $P E$ premature ejaculation, $P E D T$ premature ejaculation diagnostic tool, SBP systolic blood pressure, Stdev standard deviation of mean glucose

Therefore, the study population consisted of 112 type 1 diabetic men (Fig. 1). The clinical and metabolic characteristics of participants in the study are described in Table 1. The mean age was 25.8 years, and the mean duration of diabetes was 14 years; $47 \%$ of the overall population had a $\mathrm{BMI} \geq 25 \mathrm{~kg} / \mathrm{m}^{2}$, and $76 \%$ had $\mathrm{HbA}_{1 \mathrm{c}}>7 \%$. Sixty-eight men were treated with multiple daily injections of insulin (MDI), while the remaining 44 patients were on continuous subcutaneous insulin infusion (CSII). Compared with men on CSII, those on MDI received a higher daily insulin dose. Nine out 112 men (9\%) had microvascular complications, of which the most frequent was diabetic retinopathy, which was found in six men. The overall prevalence rates of ED and PE were $25 \%$ and $13 \%$, respectively. Among men with microvascular complications, six (67\%) had ED and three (33\%) had PE.

Twenty-six percent of diabetic men had high GV $(\mathrm{CV} \geq 36 \%$, group 1$)$. There were no differences between men with high (group 1) and low GV (group 2) in all the studied clinical variables, except for $\mathrm{CV}$ (group 1 vs group $2,47.6 \pm 9.2$ vs $27.1 \pm 6.2, P<0.001)$, TIR $(60.4 \pm 7.4$ vs $75.6 \pm 6.9, P<0.001)$, and $\operatorname{Stdev}[4.5(3.7,5.4)$ vs $2.7(2.2$, $3.2), P<0.001]$, which, as expected, were higher in group 1 than in group 2 (Table 2). ED and PE prevalence rates in group 1 were $26 \%$ and $13 \%$, respectively. Similarly, in group 2 (diabetic men with low GV), the prevalence of ED was $24 \%$, and the prevalence of PE was $13 \%$. Among patients with microvascular complications, one man in group 1 and two men in group 2 had both ED and PE.

Correlation coefficients between metabolic and psychosocial variables in diabetic men are reported in Table 2. IIEF-5 score was negatively correlated with age $(r=-0.8$; $P \leq 0.01)$, duration of diabetes $(r=-0.5 ; P \leq 0.01)$, weight $(r=-0.2 ; P=0.02)$, BMI $(r=-0.2 ; P=0.02)$, waist circumference $(r=-0.4 ; P \leq 0.01)$, and BDI $(r=-0.7$; $P \leq 0.01)$. Likewise, we found a significant association between PEDT score and age $(r=0.7 ; P \leq 0.01)$, duration of diabetes $(r=0.4 ; P \leq 0.01)$, and BDI $(r=0.5 ; P \leq 0.01)$ (Table 3). No significant associations between sexual dysfunctions and parameters of GV were observed.

In the multiple regression analysis (Table 4), in which IIEF-5 score and PEDT score were the dependent variables, only age and BDI score resulted as independent predictors of IIEF-5 score ( $\beta$ coefficient $=-0.322, P<0.001$ and $\beta$ coefficient $=-0.569, P \leq 0.001$, respectively) and PEDT score ( $\beta$ coefficient $=0.302, P<0.001$ and $\beta$ coefficient $=0.567$, $P \leq 0.001$, respectively).

\section{Discussion}

To the best of our knowledge, this is the first study evaluating the prevalence of sexual dysfunctions in a population of young type 1 diabetic men with high or low GV. We found that the prevalence of sexual dysfunctions in diabetic men with high GV was comparable to that of diabetic men with low GV. Moreover, ED was observed to be the most common sexual dysfunction in this population. The young age of the study participants, the relatively large number of 
Table 2 Characteristics of diabetic patients with high (group $1, \mathrm{CV} \geq 36 \%$ ) and low $\mathrm{GV}$ (group $2, \mathrm{CV}<36 \%$ )

\begin{tabular}{lllr}
\hline Variable & Group 1 $(n=23)$ & Group 2 $(n=89)$ & $P$ \\
\hline Age, years & $24.1 \pm 6.7$ & $26.3 \pm 7.6$ & 0.226 \\
Diabetes duration, years & $12.1 \pm 5.7$ & $14.5 \pm 6.8$ & 0.129 \\
Weight, kg & $74.5 \pm 8.8$ & $76.4 \pm 12.5$ & 0.512 \\
BMI, kg/m ${ }^{2}$ & $24.7 \pm 2.9$ & $25.1 \pm 3.4$ & 0.623 \\
WC, cm & $83.1 \pm 8.4$ & $84.1 \pm 9.1$ & 0.685 \\
FG, mg/dL & $189 \pm 72$ & $163 \pm 68$ & 0.139 \\
HbA1c, $\%$ & $7.8 \pm 1.2$ & $7.8 \pm 1.3$ & 0.989 \\
Testosterone, nmol/L & $23.9 \pm 4.3$ & $23.2 \pm 4.2$ & 0.480 \\
Microvascular complications, $n(\%)$ & $2(8.7)$ & $7(7.8)$ & 0.764 \\
CV, $\%$ & $47.6 \pm 9.2$ & $27.1 \pm 6.2$ & $<0.001$ \\
TIR, $\%$ & $60.4 \pm 7.4$ & $75.6 \pm 6.9$ & $<0.001$ \\
Mean daily glucose, mmol/L & $9.5(8.3,10.1)$ & $9.5(8.3,11.7)$ & 0.515 \\
Stdev & $4.5(3.7,5.4)$ & $2.7(2.2,3.2)$ & $<0.001$ \\
IIEF-5 score & $23(21,24)$ & $23(20,25)$ & 0.669 \\
Men with ED, $n(\%)$ & $6(26)$ & $22(25)$ & 0.893 \\
PEDT score & $2(1,4)$ & $3(1,6)$ & 0.534 \\
Men with PE, $n(\%)$ & $3(13)$ & $10(11)$ & 0.901 \\
BDI & $2(1,3)$ & $2(1,3)$ & 0.679 \\
\hline
\end{tabular}

Data are expressed as mean $\pm \mathrm{SD}$, median (interquartile range), or number and percentage. Abbreviations: $B D I$ beck depression inventory, $B M I$ body mass index, $C V$ coefficient of variation, $E D$ erectile dysfunction, $F G$ fasting glucose, IIEF-5 international index of erectile function-5, $P E$ premature ejaculation, $P E D T$ premature ejaculation diagnostic tool, Stdev standard deviation of mean glucose, TIR time in range, WC waist circumference men included ( $n=112$ ), and the possibility to differentiate between men with high and low GV are distinctive characteristics of this study.

Table 3 Correlation between IIEF-5 score, PEDT score, and metabolic and psychological domains in type 1 diabetic patients

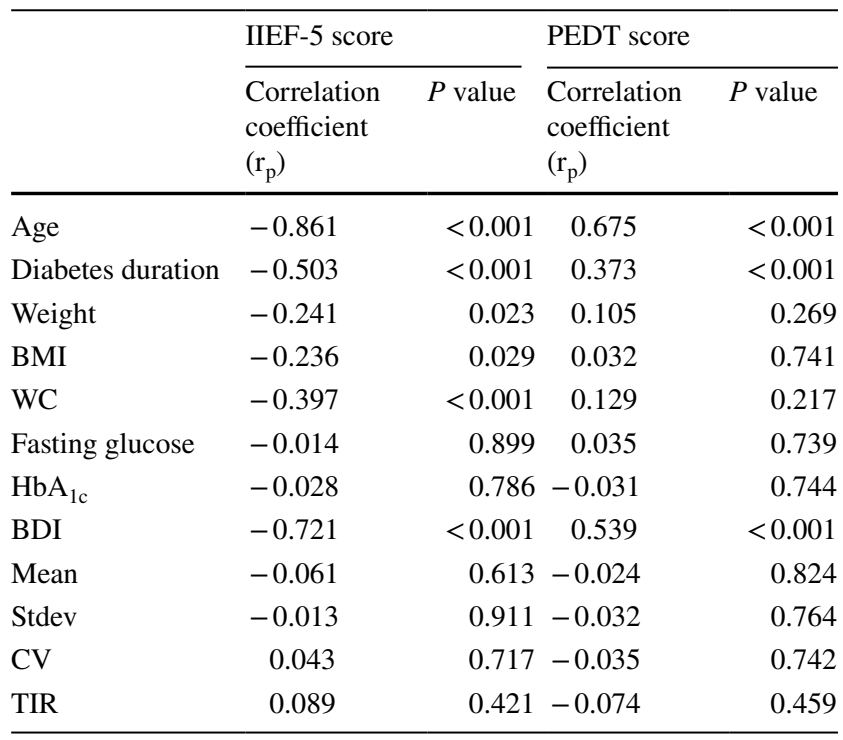

Abbreviations: $B D I$ beck depression inventory, $B M I$ body mass index, $C V$ coefficient of variation, $F G$ fasting glucose, $L D L$ low density lipoprotein, Stdev standard deviation, TIR time in range, WC waist circumference
Literature data on the prevalence of sexual dysfunctions in young men affected by type 1 diabetes are scant. Moreover, the lack of any other study describing sexual function in diabetic patients according to the degree of GV does not enable comparisons to be made.

$\mathrm{GV}$ represents an emerging determinant of vascular complications associated with diabetes [24]. One possible reason for the absence of any association between GV and sexual dysfunction in the included population may concern the measurement of glucose fluctuation in a short period of time. Indeed, the CV for glucose has been accepted as the most appropriate index for assessing the within-day glycemic variability, with a cut-off threshold value of $36 \%$ to

Table 4 Multiple regression analysis

\begin{tabular}{llrllrr}
\hline & \multicolumn{2}{l}{ IIEF-5 score } & & & PEDT score & \\
\cline { 2 - 3 } & $\beta$ coefficient & $P$ value & & B coefficient & $P$ value \\
\hline Age & -0.322 & $<0.001$ & 0.302 & $<0.001$ \\
Diabetes duration & -0.032 & 0.361 & 0.033 & 0.487 \\
Weight & -0.023 & 0.551 & -0.021 & 0.653 \\
BMI & -0.196 & 0.135 & 0.128 & 0.444 \\
WC & -0.049 & 0.241 & -0.162 & 0.006 \\
BDI & -0.569 & $<0.001$ & 0.567 & $<0.001$ \\
\hline
\end{tabular}

Abbreviations: $B D I$ beck depression inventory, $B M I$ body mass index, $W C$ waist circumference 
differentiate stable from labile glucose control [29]. At present, there is no evidence that short-term GV is an independent risk factor for cardiovascular complications in diabetes. Moreover, whether long-term GV, measured as monthly or quarterly changes in either $\mathrm{HbA} 1 \mathrm{c}$, fasting, or postprandial plasma glucose is associated with sexual disorders in men with type 1 diabetes, remains unknown.

Evidence linking glycemic control to sexual dysfunctions in men with type 1 diabetes is limited. Longitudinal analyses from the follow-up study of the Diabetes Control and Complications Trial (DCCT) suggest that glycemic control, together with age and BMI, is a predictor of ED [31]. In the same study, men who never reported ED or in only 1 isolated year of the follow-up had better glycemic control than men who had intermittent and persistent ED at DCCT baseline [31]. Moreover, in men with long-standing type 1 diabetes, elevated $\mathrm{HbA} 1 \mathrm{c}$ levels were associated with sexual dysfunctions [32]. Whether the improvement of glycemic control may help prevent sexual dysfunction or restore erectile function in type 1 diabetes remains controversial [31,33].

Diabetes, together with overweight/obesity, metabolic syndrome, and hyperlipidemia, are well-known risk factors for ED [34]. Of note, $47 \%$ of the overall diabetic population was overweight, suggesting the importance of metabolic factors in the pathogenesis of erectile complaints even in young men. On the other hand, the risk factors for PE were investigated to a lesser extent than ED. There is evidence from a cross-sectional study of young diabetic men with PE that a higher GV in the hypoglycemic domain may be significantly associated with the severity of this sexual complaint according to the calculated PEDT score [35]. However, confirming previous evidence [10], only age and depression were found to be an independent predictor of sexual function in the present study, highlighting that psychological rather than biological factors may play a major role in development of sexual dysfunctions even in young men with type 1 diabetes.

$\mathrm{PE}$ is known to be the most frequent sexual dysfunction in men, affecting nearly $23 \%$ of individuals worldwide and without significant variation in age among men over 24 years [14]. On the other hand, the prevalence of ED in men younger than 40 years ranges from 1 to $10 \%$ [3]. Our data show that the prevalence of ED is higher than that of PE in participants in the study, suggesting that among people with diabetes, there would be an inverse prevalence trend in sexual dysfunctions as compared to the general population. It is well known that ED may occur earlier in diabetes [4]. Moreover, both PE and ED were self-reported based on validated questionnaires, and this cannot fully substitute for physician-patient interaction and clinical examination in obtaining a diagnosis. Other potential reasons for this discrepancy are the possibility that younger men presenting short latencies may have a higher threshold for defining rapid ejaculation as a lack of ejaculatory control [14].

Age has been suggested as an important risk factor for sexual dysfunction in men. A cross-sectional analysis of 2126 adult male NHANES participants reported that in men at least 20 years old, ED affected almost one in five respondents to the survey, with prevalence rates increasing dramatically with advanced age [36]. On the other hand, younger individuals do not appear to be at higher risk for PE than older individuals up to the age of 59 [14].

Early adulthood is characterized by psychosocial challenges, which may be increased by the presence of diabetes [37]. Psychological disorders are also associated with male sexual dysfunctions. The association of depression with ED is well-established, both in the general population [38] and in diabetic patients [39]. Previous studies have shown that sexual function is more closely linked with depression than other diabetic complications in men and women [40]. Moreover, in several observational studies, men with PE were more likely to self-report both depression and anxiety [14, 41]. Interestingly, in 1206 men diagnosed with PE, depression was associated with PE duration and IIEF-5 scores lower than 22 [42].

This study has a number of limitations. First, due to its cross-sectional nature, we are not able to draw conclusions regarding cause and effect. Second, we did not distinguish between lifelong and acquired PE. Third, the presence of sexual dysfunctions was self-reported, and this could have introduced some bias. Major strengths of this study include the use of a validated tool for the evaluation of sexual dysfunction, the relatively large number of subjects investigated, and the contemporary evaluation of many aspects of life linked to sexual function (depression and general health status).

In conclusion, young male patients affected by type 1 diabetes with high or low GV show a similar prevalence of sexual dysfunctions. ED was shown to be the most common sexual dysfunction in diabetic men. Age and depression were the only independent predictive factors for sexual dysfunctions in this selected population. The role of glycemic control in the pathogenesis of sexual dysfunctions in men with type 1 diabetes remains to be clarified. Meanwhile, evaluation of psychosocial factors should be encouraged in young type 1 diabetic men with sexual dysfunctions.

Authors' contributions Conceptualization: Paola Caruso, Maria Ida Maiorino, and Katherine Esposito. Formal analysis: Maria Ida Maiorino and Giuseppe Bellastella. Funding acquisition: Katherine Esposito. Investigation, Paola Caruso, Paolo Cirillo, Carla Carbone, and Annalisa Sarnataro. Methodology: Maria Ida Maiorino and Katherine Esposito. Project administration: Katherine Esposito. Supervision: Giuseppe Bellastella. Writing, original draft: Paola Caruso and 
Maria Ida Maiorino. Writing, review and editing: Paolo Cirillo, Carla Carbone, Annalisa Sarnataro, Giuseppe Bellastella, and Katherine Esposito.

Funding Open access funding provided by Università degli Studi della Campania Luigi Vanvitelli within the CRUI-CARE Agreement. This research was funded by the Italian Ministry of University and Research (PRIN 2017, protocol 2017XLFJAX, cod B64I17000080001). The funders had no role in the design of the study; in the collection, analyses, or interpretation of data; in the writing of the manuscript, or in the decision to publish the results.

Data availability All data generated or analyzed during this study are included in this published article.

Code availability Not applicable.

\section{Declarations}

Ethics approval This study was performed in line with the principles of the Declaration of Helsinki. Approval was granted by the Ethics Committee of University of Campania Luigi Vanvitelli and AORN Ospedale dei Colli (Date 24.01.2013/N Prot 32).

Informed consent Informed consent was obtained from all individual participants included in the study.

Consent to participate All subjects gave their informed consent for inclusion before they participated in the study.

Consent for publication Not applicable.

Conflict of interest The authors declare no competing interests.

Open Access This article is licensed under a Creative Commons Attribution 4.0 International License, which permits use, sharing, adaptation, distribution and reproduction in any medium or format, as long as you give appropriate credit to the original author(s) and the source, provide a link to the Creative Commons licence, and indicate if changes were made. The images or other third party material in this article are included in the article's Creative Commons licence, unless indicated otherwise in a credit line to the material. If material is not included in the article's Creative Commons licence and your intended use is not permitted by statutory regulation or exceeds the permitted use, you will need to obtain permission directly from the copyright holder. To view a copy of this licence, visit http://creativecommons.org/licenses/by/4.0/.

\section{References}

1. Maiorino MI, Bellastella G, Esposito K (2014) Diabetes and sexual dysfunction: current perspectives. Diabetes Metab Syndr Obes 7:95-105

2. McCabe MP, Sharlip ID, Atalla E et al (2016) Definitions of sexual dysfunctions in women and men: a consensus statement from the fourth international consultation on sexual medicine 2015. J Sex Med 13:135-143

3. McCabe MP, Sharlip ID, Lewis R et al (2016) Incidence and prevalence of sexual dysfunction in women and men: a consensus statement from the fourth international consultation on sexual medicine 2015. J Sex Med 13:144-152
4. Feldman HA, Goldstein I, Hatzichristou DG, Krane RJ, McKinlay JB (1994) Impotence and its medical and psychosocial correlates: results of the Massachusetts Male Aging Study. J Urol 151:54-61

5. Penson DF, Latini DM, Lubeck DP, Wallace KL, Henning JM, Lue TF (2003) Comprehensive evaluation of erectile dysfunction (ExCEED) database. Do impotent men with diabetes have more severe erectile dysfunction and worse quality of life than the general population of impotent patients? Results from the Exploratory Comprehensive Evaluation of Erectile Dysfunction (ExCEED) database. Diabetes Care 26:1093-1099

6. Goldstein I, Lue TF, Padma-Nathan H, Rosen RC, Steers WD, Wicker PA (1994) Oral sildenafil in the treatment of erectile dysfunction. Sildenafil Study Group. N Engl J Med 338:1397-1404

7. Corona G, Giorda CB, Cucinotta D, Guida P, Nada E, Gruppo di studio SUBITO-DE, (2013) The SUBITO-DE study: sexual dysfunction in newly diagnosed type 2 diabetes male patients. $\mathrm{J}$ Endocrinol Invest 36:864-868

8. De Berardis G, Franciosi M, Belfiglio M et al (2002) Erectile dysfunction and quality of life in type 2 diabetic patients: a serious problem too often overlooked. Diabetes Care 25:284-291

9. Giugliano F, Maiorino M, Bellastella G, Gicchino M, Giugliano D, Esposito K (2010) Determinants of erectile dysfunction in type 2 diabetes. Int J Impot Res 22:204-209

10. Maiorino MI, Bellastella G, Della Volpe E et al (2017) Erectile dysfunction in young men with type 1 diabetes. Int J Impot Res 29:17-22

11. Al-Hunayan A, Al-Mutar M, Kehinde EO, Thalib L, Al-Ghorory $M$ (2007) The prevalence and predictors of erectile dysfunction in men with newly diagnosed with type 2 diabetes mellitus. BJU Int 99:130-134

12. Serefoglu EC, McMahon CG, Waldinger MD et al (2014) An evidence-based unified definition of lifelong and acquired premature ejaculation: report of the second international society for sexual medicine ad hoc committee for the definition of premature ejaculation. Sex Med 2:41-59

13. Majzoub A, Arafa M, Al-Said S, Dabbous Z, Aboulsoud S, Khalafalla K et al (2016) Premature ejaculation in type II diabetes mellitus patients: association with glycemic control. Transl Androl Urol 5:248-254

14. Porst H, Montorsi F, Rosen RC, Gaynor L, Grupe S, Alexander J (2007) The Premature Ejaculation Prevalence and Attitudes (PEPA) survey: prevalence, comorbidities, and professional help-seeking. Eur Urol 51:816-823

15. Kouidrat Y, Pizzol D, Cosco T, Thompson T, Carnaghi M, Bertoldo A, Solmi M, Stubbs B, Veronese N (2017) High prevalence of erectile dysfunction in diabetes: a systematic review and meta-analysis of 145 studies. Diabet Med 34:1185-1192

16. Reichard P, Nilsson BY, Rosenqvist U (1993) The effect of long-term intensified insulin treatment on the development of microvascular complications of diabetes mellitus. N Engl J Med 329:304-309

17. Ang L, Jaiswal M, Martin C (2014) Pop-Busui R (2014) Glucose control and diabetic neuropathy: lessons from recent large clinical trials. Curr Diab Rep 14:528

18. The DCCT/EDIC Research Group (2002) The effect of intensive therapy on the microvascular complications of type 1 diabetes mellitus. JAMA 287:2563-2569

19. Lachin JM, Bebu I, Bergenstal RM, Pop-Busui R, Service FJ, Zinman B, Nathan DM, DCCT/EDIC Research Group (2017) Association of glycemic variability in type 1 diabetes with progression of microvascular outcomes in the diabetes control and complications trial. Diabetes Care 40:777-783

20. The DCCT Research Group (1995) The effect of intensive diabetes treatment on the progression of diabetic retinopathy in insulin-dependent diabetes mellitus: the diabetes control and complication trial. Arch Ophthalmol 113:36-51 
21. Bragd J, Adamson U, Bäcklund LB, Lins PE, Moberg E, Oskarsson P (2008) Can glycaemic variability, as calculated from blood glucose self-monitoring, predict the development of complications in type 1 diabetes over a decade? Diabetes Metab 34:612-616

22. Gimeno-Orna JA, Castro-Alonso FJ, Boned-Juliani B, LouArnal LM (2003) Fasting plasma glucose variability as a risk factor of retinopathy in type 2 diabetic patients. J Diabetes Complications 17:78-81

23. DeVries JH (2013) Glucose variability: where it is important and how to measure it. Diabetes 62:1405-1408

24. Dandona P (2017) Minimizing glycemic fluctuations in patients with type 2 diabetes: approaches and importance. Diabetes Technol Ther 19:498-506

25. Rosen RC, Cappelleri JC, Smith MD, Lipsky J, Peña BM (1999) Development and evaluation of an abridged, 5-item version of the International Index of Erectile Function (IIEF-5) as a diagnostic tool for erectile dysfunction. Int J Impot Res 11:319-326

26. Hatzimouratidis K, Amar E, Eardley I, Giuliano F, Hatzichristou D, Montorsi F, Vardi Y, Wespes E, European Association of Urology (2010) Guidelines on male sexual dysfunction: erectile dysfunction and premature ejaculation. Eur Urol 57:804-814

27. Symonds T, Perelman MA, Althof S (2007) Development and validation of a premature ejaculation diagnostic tool. Eur Urol 52:565-573

28. Richter P, Werner J, Heerlein A, Kraus A, Sauer H (1998) On the validity of the Beck Depression Inventory. A review. Psychopathology 31:160-168

29. Battelino T, Danne T, Bergenstal RM et al (2019) Clinical targets for continuous glucose monitoring data interpretation: recommendations from the international consensus on time in range. Diabetes Care 42:1593-1603

30. Longo M, Scappaticcio L, Castaldo F, METRO study group (2021) Sexual dysfunctions in young women with type 1 diabetes and high glucose variability: findings from the METRO study. J Endocrinol Invest 43:1823-1825

31. Palmer MR, Holt SK, Sarma AV et al (2017) Longitudinal patterns of occurrence and remission of erectile dysfunction in men with type 1 diabetes. J Sex Med 14:1187-1194

32. Turek SJ, Hastings SM, Sun JK, King GL, Keenan HA (2013) Sexual dysfunction as a marker of cardiovascular disease in males with 50 or more years of type 1 diabetes. Diabetes Care 36:3222-3226

33. Wessells H, Penson DF, Cleary P et al (2011) Effect of intensive glycemic therapy on erectile function in men with type 1 diabetes. J Urol 185:1828-1834
34. McCabe MP, Sharlip ID, Lewis R et al (2016) Risk factors for sexual dysfunction among women and men: a consensus statement from the fourth international consultation on sexual medicine 2015. J Sex Med 13:153-167

35. Bellastella G, Maiorino MI, Olita L et al (2015) Della Volpe E, Giugliano D, Esposito K. Premature ejaculation is associated with glycemic control in Type 1 diabetes. J Sex Med 12:93-99

36. Selvin E, Burnett AL, Platz EA (2007) Prevalence and risk factors for ED in the US. Am J Med 120:151

37. Peters A, Laffel L (2011) American Diabetes Association Transitions Working Group Diabetes care for emerging adults: recommendations for transition from pediatric to adult diabetes care systems: a position statement of the American Diabetes Association, with representation by the American College of Osteopathic Family Physicians, the American Academy of Pediatrics, the American Association of Clinical Endocrinologists, the American Osteopathic Association, the Centers for Disease Control and Prevention, Children with Diabetes, The Endocrine Society, the International Society for Pediatric and Adolescent Diabetes, Juvenile Diabetes Research Foundation International, the National Diabetes Education Program, and the Pediatric Endocrine Society (formerly Lawson Wilkins Pediatric Endocrine Society). Diabetes Care 34:2477-2485

38. Araujo AB, Durante R, Feldman HA, Goldstein I, McKinlay JB (1998) The relationship between depressive symptoms and male erectile dysfunction: cross-sectional results from the Massachusetts Male Aging Study. Psychosom Med 60:458-465

39. De Berardis G, Pellegrini F, Franciosi M et al (2007) Clinical and psychological predictors of incidence of self-reported erectile dysfunction in patients with type 2 diabetes. J Urol 177:252-257

40. de Groot M, Anderson R, Freedland K et al (2001) Association of depression and diabetes complications: a meta-analysis. Psychosom Med 63:619-630

41. Son H, Song SH, Lee JY, Paick JS (2011) Relationship between premature ejaculation and depression in Korean males. J Sex Med 8:2062-2070

42. Zhang H, Yip AW, Fan S et al (2013) Sexual dysfunction among Chinese married men aged 30e60 years: a population-based study in Hong Kong. Urology 81:334

Publisher's note Springer Nature remains neutral with regard to jurisdictional claims in published maps and institutional affiliations. 